\title{
HISTÓRIAS DE (RE) EDIÇÃO DE UM SCRIPT EM INGLÊS POR MEIO DO GOOGLE DOCS: O PROFESSOR E A COLABORAÇÃO
}

\section{STORIES OF SCRIPT (RE) EDITING IN ENGLISH BY GOOGLE DOCS: THE TEACHER AND THE COLLABORATION}

\author{
Gilmar Martins de F. FERNANDES (CEFET-MG / PPGEL-UFU) ${ }^{1}$
}

\begin{abstract}
Resumo: Na contemporaneidade, considerando a evolução das tecnologias digitais, surgem novas possibilidades de ensino-aprendizagem em contextos online por meio de uma interconectividade negociada. Nesse cenário, algumas ferramentas digitais parecem favorecer o trabalho, o ensino e a aprendizagem de forma colaborativa e cooperativa. Portanto, neste artigo, objetivo narrar e analisar uma experiência de (re) escrita de um script em língua inglesa, por meio da ferramenta digital Google Docs. Participaram desta investigação narrativa seis alunos do terceiro ano do Ensino Médio de um Curso Técnico em Mineração. Desenvolvo esta pesquisa sob a perspectiva teórico-metodológica da Pesquisa Narrativa, seguindo o caminho epistemológico proposto por Clandinin e Connelly (2000, 2011 et al). Analiso as experiências (re) vividas e (re) contadas pelo processo de composição de sentidos, como estabelecido pelos autores Ely, Vinz, Downing e Anzul (2001). A partir das experiências vividas e dos sentidos compostos foi possível identificar, dentre outras questões, que a ferramenta digital Google Docs pode favorecer o desenvolvimento da habilidade de escrita dos alunos em língua inglesa e que o planejamento gerenciamento das atividades e, principalmente, o envolvimento do professor no processo de (re) escrita podem contribuir para o trabalho colaborativo.
\end{abstract}

PALAVRAS-CHAVE: Colaboração; Língua Inglesa; Script; Google Docs.

\begin{abstract}
In modern times, due technological evolution, new ways of teaching and learning come up on online contexts by a negotiated interconnectivity. In this setting some digital tools seem to benefit collaborative, and cooperative, work, learning, and teaching. Therefore, in this article I aim to tell and analyze a collaborative and cooperative script writing experience in English by the digital tool Google Docs. It took part of this Narrative Inquiry six students at a High School level from a Mining Certification Program. I carry out this research under the Narrative Inquiry theoreticalmethodological perspective, following the epistemological way encouraged by Clandinin and Connelly $(2000,2011$ et al). I analyze the (re) lived and (re) told experiences by the meaning composing process, as stated by the authors Ely, Vinz, Downing and Anzul (2001). From the lived experiences and the meanings composed it was possible to notice, among other issues, that the digital tool Google Docs can benefit the development of students' English writing skills and that the activity planning - management, and the teacher engagement in the (re) writing process can contribute to the collaborative work.
\end{abstract}

KEYWORDS: Collaboration; English Language; Script; Google Docs.

\section{INTRODUÇÃO}

\footnotetext{
${ }^{1}$ Mestre em Estudos Linguísticos e discente do curso de doutorado pelo Programa de Pós-Graduação em Estudos Linguísticos da Universidade Federal de Uberlândia (2014). Atualmente é professor de língua inglesa no Centro Federal de Educação Tecnológica de Minas Gerais, campus de Araxá e, também, pesquisador na Saint Mary's University, universidade localizada em Halifax, Canadá. Tem experiência na área de Letras, com ênfase em Língua Inglesa, ensino e aprendizagem de línguas mediados por tecnologias, atuando principalmente nos seguintes temas: formação de professores de língua inglesa, uso de tecnologias digitais para ensino-aprendizagem, relação brasil-canadá, língua inglesa e Pesquisa Narrativa. gilmar tins@ytahoo.com.br
} 
Atualmente, devido a rápida e, em alguns casos, assustadora evolução das tecnologias digitais da comunicação e informação (AFONSO, 2002), a sociedade se vê permeada e dependente de várias tecnologias para realizar das mais banais às mais complexas atividades. Ir ao supermercado, ao banco, falar com um amigo, hoje, frequentemente, tem como mediador alguma tecnologia digital: cartão de crédito, caixa eletrônico e celular, por exemplo. Nesse contexto, os processos de ensino e aprendizagem, são, também, frequentemente, influenciados e mediados por alguma tecnologia digital: vídeoaulas, tutoriais, podcasts, aplicativos de línguas estrangeiras, jogos educativos, tradutores online, salas de bate-papo, redes sociais, redes colaborativas como wikis e blogs, dentre outras.

Imersos nesse universo digital (FERNANDES, 2014) da contemporaneidade, alunos e professores se veem, também, interpelados a utilizar diversas tecnologias em contextos (in) formais para fins diversos. No que concerne às práticas da sala de aula de língua inglesa, presencial ou a distância, algumas tecnologias digitais (TDICs) têm o potencial de contribuir para o ensino e aprendizagem de forma colaborativa e/ou cooperativa. Contudo, a mera utilização de uma TDIC não contribui para que esses processos possam ser, de fato, colaborativos-cooperativos. Portanto, neste artigo objetivo narrar e analisar uma experiência de (re) escrita de um script em língua inglesa, vivida por seis alunos do terceiro ano do Ensino Médio integrado ao Curso Técnico em Mineração, por meio da ferramenta digital Google Docs ${ }^{i}$ (frequentemente referido, neste artigo, como GD), atentando para as possibilidades de colaboração-cooperação por meio dessa experiência.

\section{CONTEXTO}

Nesta pesquisaii, seis alunos de uma turma de terceiro ano do ensino médio, de um centro federal de educação técnica, foram solicitados a fazerem um vídeo em língua inglesa para apresentar e explicar algumas especificidades do curso técnico que fazem, a saber, o Curso de Mineração. Nessa atividade, eu, professor de Língua Inglesa desses alunos, pedi que eles elaborassem um script em inglês para que pudessem fazer o vídeo, no qual narrariam questões específicas do curso que fazem e da escola que estudam. $O$ objetivo da atividade era desenvolver a habilidade de escrita em língua inglesa, por isso, escolhi o gênero script. Contudo, a habilidade de produção oral poderia ser, também, contemplada, mas, nesse caso, seria apenas dos alunos que narrassem o script criado. 
As experiências recontadas neste artigo foram vivenciadas por Luís F., Luíza, Sara L., Sara C., Thaís e Robson. Considerando o aspecto ético-relacional da Pesquisa Narrativa (CLANDININ, 2013), os textos de campo e a composição de sentidos aqui empreendida foram apresentadas aos participantes e eles, por sua vez, fizeram algumas considerações. Do mesmo modo, respeitando o desejo dos participantes, seus nomes reais foram mantidos. Eu escolhi esses participantes para esta pesquisa, pois, por eles terem, de forma geral, um conhecimento considerável da língua inglesa, eu acreditava que não haveria colaboração entre eles e que, ocasionalmente, um ou outro criaria o script. Contudo, ao analisar as atividades realizadas, constatei que eu estava equivocado.

A atividade foi realizada dentro e fora da sala de aula e se deu em quatro momentos: no primeiro momento, eu lhes apresentei, em sala de aula, alguns vídeos em que alunos de universidades estrangeiras apresentavam suas escolas; no segundo, os alunos elaboraram, sozinhos, um script do que pretendiam falar no vídeo; no terceiro, os alunos me enviaram o script e eu os levei a um laboratório de informática, por duas vezes, para que juntos pudéssemos fazer correções, pesquisas e alterações no script criado por eles; no quarto, os alunos usaram o script elaborado para criarem um vídeo em inglês ${ }^{\mathrm{iii}}$ com quatro minutos de duração. Toda a atividade durou, aproximadamente, um mês e meio, compreendendo todos os quatro momentos descritos anteriormente. A edição do script foi feita no intervalo de três semanas, sendo duas presencialmente, no laboratório de informática, e uma a distância.

\section{METODOLOGIA}

\section{Caminho teórico-metodológico: a Pesquisa Narrativa}

Realizo esta pesquisa sob o caminho teórico-metodológico da Pesquisa Narrativa (CAINE E CLANDININ, 2013; CLANDININ, 2007; CLANDININ E CONNELY, 1998, 2000, 2011; CLANDININ et al, 2007; CONNELLY E CLANDININ, 1990, 1994; DEWEY, 1938, 1979; MELLO, 2005, 2008, 2007, 2012A, 2012B, 2016; KING, 2003 et al), perspectiva científica que me possibilita investigar as experiências vividas com meus alunos na (re) escrita do script a partir do (re) viver e (re) contar de nossas histórias. Conforme Clandinin e Connelly (1998), as histórias de vida são, na verdade, quem nós somos no mundo, por isso, as experiências que vivemos oferecem possibilidades de compreendermos e compormos novos sentidos de quem somos. 
De acordo com Dewey $(1938,1979)$, as experiências que vivemos no presente são mudadas pelas experiências que vivemos no passado e mudarão as experiências que viveremos no futuro. Nesse sentido, segundo o autor, é importante que o educador, como pessoa mais madura, auxilie o aprendiz para que este consiga lidar com as novas experiências que viverá. Assim sendo, neste artigo, as experiências vividas pelos alunos e por mim serão recontadas com o objetivo de investigar como elas podem contribuir para a escrita colaborativa de um script em inglês, um gênero novo para os alunos.

\section{Composição de sentidos}

Os sentidos compostos das experiências vividas, e narradas neste artigo, por mim, o pesquisador e professor de língua inglesa, e os demais participantes, seis alunos do ensino médio, são feitos pelo processo de composição de sentidos (ELY et al, 2001). Conforme os autores, a composição de sentidos é um processo de (re) contar as experiências vividas, que tem o intuito de analisar, reviver e compor novos sentidos das histórias de vida que vivemos e que compartilhamos por meio de narrativas.

Conforme Clandinin e Connelly $(2000,2011)$, os textos de campo são fundamentais para a reconstrução das experiências vividas e, sobretudo, para a composição de sentidos. Assim, neste artigo, meus textos de campo são: os registros das alterações feitas pelos alunos no documento do Google Docs, as versões do script criadas a partir da interação entre os alunos e eu, minhas observações e reconstruções de memória sobre as atividades realizadas no laboratório de informática.

\section{COLABORAÇÃO}

Devido ao avanço e presença das tecnologias digitais em diversos contextos da sociedade contemporânea, alguns pesquisadores têm analisado como tais tecnologias têm contribuído no processo de aprendizagem, de questões variadas, e como elas podem ser utilizadas para/no desenvolvimento de atividades de cunho colaborativo (BEDRAN; 2015; DILLENBOURG, 1999; FIGUEIREDO E SILVA, 2014; ONRUBIA et al, 2010; MACHADO, 2009A, 2009B; ROSCHELLE E TEASLEY, 1995; WEISSHEIMER et al, 2012 et al). Por meio de pesquisas quantitativas e qualitativas, pesquisadores se atentam para questões de ordem linguísticas, discursivas, gramaticais e relacionais que podem contribuir para o aprimoramento ou desenvolvimento de habilidades linguísticas em uma língua estrangeira. 
No estudo realizado por Weissheimer, Bergsleither e Leandro (2012), por exemplo, os pesquisadores investigaram como a escrita colaborativa de flash fictions, por meio da ferramenta Google Docs, poderia contribuir para o aprimoramento de questões gramaticais da língua inglesa. A partir de um estudo quantitativo e qualitativo, os pesquisadores identificaram que o processo de escrita colaborativa possibilitou que os participantes aprimorassem seus conhecimentos gramaticais da língua porque, ao serem corrigidos pelos colegas, eles puderam perceber e corrigir erros que antes não notavam.

Além disso, o estudo revelou que os participantes se preocuparam mais com a questão discursiva na elaboração e correção das flash fictions que apenas questões gramaticais. De acordo com os autores, isso, provavelmente, ocorreu devido a não interferência dos professores nesse processo, que contribuiu para que os alunos focassem em questões do gênero em detrimento de aspectos formais da língua inglesa. Em sua maioria, os participantes da pesquisa afirmaram que o processo de colaboração para a escrita de histórias fictícias curtas contribuiu para que aprendessem questões linguísticas antes despercebidas.

Conforme apontado por Lamy e Hampel (2007), as tecnologias digitais têm tido grande impacto nos papeis assumidos por professores e alunos devido às amplas possibilidades de ensino e aprendizagem por meio delas. No contexto das TDICs, ensinar e aprender de forma colaborativa e cooperativa tem sido cada vez mais relevante. Assim, o professor já não tem o papel de dar as respostas, mas de guiar o aluno a buscar conhecimento. $\mathrm{O}$ aluno, por sua vez, tem a possibilidade de estabelecer redes de contato online para buscar os conhecimentos que deseja/precisa.

Embora a colaboração e a cooperação sejam importantes nos processos de ensino-aprendizagem, elas apresentam diferenças significativas. De acordo com Roschelle e Teasley (1995, p. 70), "um trabalho cooperativo é realizado pela divisão de trabalho entre os participantes, como uma atividade em que cada pessoa é responsável pela solução de uma parte do problema", enquanto a colaboração pode ser entendida como "um engajamento mútuo dos participantes em um esforço articulado para resolver um problema em conjunto iv".

Ante a essas concepções, a colaboração parece engendrar uma interdependência entre os participantes na, e para, alcançar um objetivo comum, de forma que um precisa do outro. A cooperação, por sua vez, engloba, também, o trabalho em equipe, mas de forma individualizada, em que um participante e/ou um grupo tem papeis e tarefas diferentes para alcançar um objetivo comum. Nesse caso, há uma independência entre os 
participantes, uma vez que o trabalho é dividido em partes e cada um é responsável por uma delas.

Segundo Dillenbourg (1999), há diferentes entendimentos sobre a aprendizagem colaborativa. Para alguns, ela é um método pedagógico e para outros ela é um processo psicológico. À primeira concepção, está associada uma ideia prescritiva, que sugere que o trabalho em equipe possibilitará uma aprendizagem mais eficiente. Já a segunda concepção traz consigo uma ideia descritiva, que postula que a colaboração é mecanismo que favorece a aprendizagem.

Entretanto, para Dillenbourg (1999), ambas as concepções supervalorizam a eficácia da aprendizagem colaborativa, pois, segundo o autor, aprendizagem colaborativa não é método, tampouco um único mecanismo. Não é método, pois este envolve questões (instruções, materiais, espaço físico, técnicas e outros) que não garantem que a aprendizagem colaborativa ocorra. Não é, também, um único mecanismo, uma vez que a aprendizagem ocorre não pelo fato de o indivíduo estar sozinho ou em conjunto, mas por estes realizarem atividades/ações que desencadeiam questões cognitivas que favorecem à aprendizagem.

Dillenbourg (1999) atesta que as interações entre os indivíduos, ambiente e atividade parecem ser primordiais para favorecerem a aprendizagem colaborativa. Nesse sentido, o autor ressalta que é importante refletir sobre algumas questões relacionadas à atividade (instruções para a atividade, divisão dos grupos, heterogeneidade dos alunos, faixa-etária, habilidades e conhecimentos individuais, suporte para a realização das atividades, feedback, dentre outras) que poderão contribuir para que interações significativas possam ocorrer e, assim, favorecer a aprendizagem colaborativa. Assim, desenvolvo este artigo compreendendo que as interações, contexto e instruções podem ser primordiais para o trabalho colaborativo e que o trabalho em equipe pode desencadear uma aprendizagem em conjunto.

\section{HISTÓRIAS DE CRIAÇÃO E EDIÇÃO: UM SCRIPT QUE PARECE NÃO TER FIM}

Nesta seção, conto as experiências vividas com meus alunos para a criação e edição do script no documento Google Docs (GD). Inicio narrando o momento das instruções para a criação do mesmo e, posteriormente, as experiências marcantes com relação ao processo de reescrita do script.

Hoje vou falar com meus alunos sobre o próximo trabalho que eles farão. Vou propor outro vídeo em inglês, mas, dessa vez, vou pedir que falem sobre a escola deles. 
No vídeo anterior, eu avaliei a produção oral de cada aluno, foram mais de duzentos vídeos que assisti, pelo menos, duas vezes cada um. Que trabalhão!!! Foi um bom trabalho para os alunos, acredito que este também será interessante para a aprendizagem de inglês. Dessa vez, vou avaliar a pronúncia também, contudo, focarei na produção escrita, por isso, vou pedir que façam um script para que possamos reconstruílo juntos. É hora de ir para aula e lhes passar algumas instruções:

\begin{abstract}
Dear students, no semestre anterior, vocês fizeram um vídeo em inglês em que falaram sobre suas vidas pessoais e sobre suas cidades. Agora, vocês poderão apresentar algumas das atividades que realizam na escola, algumas das matérias que mais gostam, o que fazem nessa matéria, o que estudam, e aprenderam, nela, e, também, apresentar o espaço físico da escola. Se quiserem, deem uma olhada no YouTube em tags como "What's in my school?" ou "My school routine" para terem como exemplo.

Usem a criatividade de vocês e elaborem um script para que possam criar um vídeo em inglês com todas essas informações. Pesquisem na internet o que dizer sobre o curso, a escola e como dizer o nome do curso e as atividades que realizam em inglês. Vocês poderão fazer esse trabalho em um grupo de até seis integrantes.

O vídeo, como no anterior, precisa ser multimodal, com fotos, imagens e, principalmente, um narrador (uma voz de um ou mais de um dos integrantes do grupo narrando o vídeo). Nesse trabalho, é importante que vocês pesquisem o que vão dizer, pois vou avaliar a pronúncia do narrador, as informações que irão passar, questões gramaticais, o envolvimento do grupo e o empenho na atividade. Usem dicionários, livros, internet, Voki ou Google Tradutor (para ouvir a pronúncia das palavras). Esse vídeo será feito para postarmos no YouTube, como uma forma de apresentar a escola de vocês a futuros alunos, então, pensem quais informações são importantes passar sobre a escola e o curso de vocês.
\end{abstract}

(Reconstrução de memória - instrução dada aos alunos, outubro de 2016).

Pronto, passei as instruções que preparei, mas é melhor perguntar se há dúvidas para que eles não se sintam perdidos:

- Guys, alguma dúvida?

- Sim, professor. Todos do grupo têm que falar no vídeo?

- Não, não precisa. Contudo, pelo menos um dos integrantes do grupo terá que narrar tudo que é mostrado no vídeo. Por isso, é importante que vocês chequem a pronúncia de todos os termos e palavras que forem usar.

- Teacher, dessa vez vamos ter que mostrar o rosto de novo?

- Não, dessa vez ficará a critério de vocês aparecerem no vídeo ou não. O importante é que vocês façam um vídeo multimodal com fotos, sons e imagens gravadas. Se atentem para a qualidade do som. Se, por acaso, vocês gravarem tudo e perceberem que em um trecho ou outro o som está ruim, não precisam gravar novamente, basta colocar legenda. Alguma outra dúvida?

- Eu tenho.

- Diga, Fabrício.

- E se nós entrevistarmos os professores e eles não falarem inglês, como fazemos?

- Ah, é simples, basta vocês colocarem legendas em inglês. Entendido?

- Sim, entendido.

(Reconstrução de memória - diálogo criado da conversa com os alunos, outubro de 2016).

Hoje foi o prazo final para os alunos me enviarem o script. Esse grupo costuma ser comprometido e pontual, vou checar se já me enviaram. Como imaginava, lá estava o email do grupo com a primeira versão do script deles: 


\section{Primeira versão do script}

Group:
Luís F.
Luiza
Sara V.
Sara C.
Thaís
Robson
Turma: $3^{\circ}$ Min
Welcome to Cefet, Federal Center of Technologicar
It is located in the city of Araxá in Minas Gerais
It has 4 technical courses that are held in conjunction with the High School
We do the course of mining and we are in the 3rd year of average education
Our course covers from opening a mine to treatment of ore removed from the mine, including softwars used
in each of the mining
(Interview with our Hildor and Michel teachers)

Fonte: print screen do texto enviado pelos alunos

Ao abrir o documento, pensei:

$\mathrm{Na}$ última aula, assistimos dois vídeos em inglês de alunos apresentando suas escolas que, acredito, contribuíram para os alunos elaborarem essa primeira versão do script que me enviaram. Esse documento que me enviaram traz informações gerais da escola como sua localização, a quantidade de cursos que oferece, o curso que eles fazem e a área de abrangência dele, mas, ele não é bem um script. Nessa aula, expliquei que gostaria que eles focassem em temas específicos do curso de Mineração e que se atentassem a questões técnicas na hora de fazer seus vídeos (volume do som, posicionamento de câmera, perguntas a serem feitas aos entrevistados, iluminação, ruídos externos etc.,), mas não discutimos sobre o que é um script. Na próxima aula, vou levá-los ao laboratório de informática para pesquisarmos juntos sobre esse gênero.

(Reconstrução de memória - a primeira versão do script, outubro de 2016).

Já é terça-feira após o almoço, estou cansado, mas é hora de voltar à sala de aula.

Pedi à secretária que me ajudasse a encontrar a chave do laboratório de informática. Peguei a chave e fui em direção à sala de aula. Meus alunos deitados no chão da escola, descansando depois do almoço, como de costume. Passei rapidamente por eles e disse "We are going to the lab today", uns, como sempre, reclamaram por hábito "Ah, não. Por quê? ". Eu, conhecendo meus alunos, dei a mesma resposta de sempre "Just do it", imitando um meme da internet.

Cheguei, destranquei o laboratório, fechei as cortinas para não dar reflexo nas telas dos computadores e liguei o ar-condicionado. "Liguem os computadores, please", falei. Liguei meu computador na última fileira. "Ready? ”, perguntei. "Não, ainda não", alguns responderam. Esperei mais um momento, abri meu email e minha pasta do Google Drive.

História secreta: o que os alunos desconhecem

"Hoje vou levar os alunos ao laboratório para eles revisarem o quase 'script' que eles me enviaram, pois me parece que eles não estão trabalhando em grupo, então, vou usar essa aula para que todos tenham a oportunidade de participar da construção do mesmo", pensei. 
Cheguei ao laboratório, fechei as cortinas para evitar reflexo do sol nos computadores, liguei o ar-condicionado e decidi sentar na última fileira, mas não foi sem propósito, articulei "vou utilizar o último computador, de lá eu consigo visualizar os computadores de todos os alunos, assim posso vigiar para ver se todos do grupo estão participando das correções do script".

Estava sempre atento e, quando necessário, chamava a atenção dos alunos "Fulano, não é hora de conversar com a colega do lado", "Você já visualizou as minhas perguntas no documento? ", "O que você está fazendo? ". Algumas vezes, eu chamei atenção de um ou outro aluno pelo chat, no corpo do documento ou em voz alta no laboratório "Não é hora de ver vídeo no YouTube, ajude seu grupo", "Não fique no what's app". Tentei fazer com que todos trabalhassem em equipe.

(Reconstrução de memória - lembrança das atividades no laboratório, outubro de 2016).

Pedi a atenção de todos, e disse "Guys, vocês me enviaram a primeira versão do script, mas o texto que recebi não é exatamente um script, então, pesquisem no Google o que é um script". Dei um tempo para pesquisarem e continuei "Bom, agora vocês concordam comigo que o texto que me enviaram não é bem um script? "Sim, concordamos porque um script tem que ter a fala de cada um, tem que ter o que será feito no começo, meio e fim". Ao ouvi-los, pedi que abrissem o email da turma para que acessassem o link que eu havia enviado, um link de um documento no GD.

Solicitei que abrissem o documento no Google Docs correspondente a segunda versão do script, a seguir. "Vejam que eu fiz alguns comentários para que vocês revisem e chequem usando o Google, dicionários e tradutores. Juntos vamos construir esse script", falei. "Isso tudo é para checar, professor? Isso tudo está errado? ", perguntou Luíza. "Não, eu marquei algumas questões que podem estar erradas, outras que podem ser ditas de outras formas, outras que não tem o mesmo sentido em inglês, ou que não fazem sentido nenhum mesmo", respondi. Disse a eles que "curso técnico", por exemplo, poderia não ser exatamente "technical course" em inglês e que "conjunction" poderia não significar "juntamente". Logo depois, pedi que pesquisassem como dizer "ensino médio" em inglês, pois "average education" não seria uma tradução adequada. Em alguns momentos Ihes fiz perguntas "Vocês são mesmo habilitados a abrir uma mina? O que querem dizer com including softwares? ".

\section{Segunda versão do script}




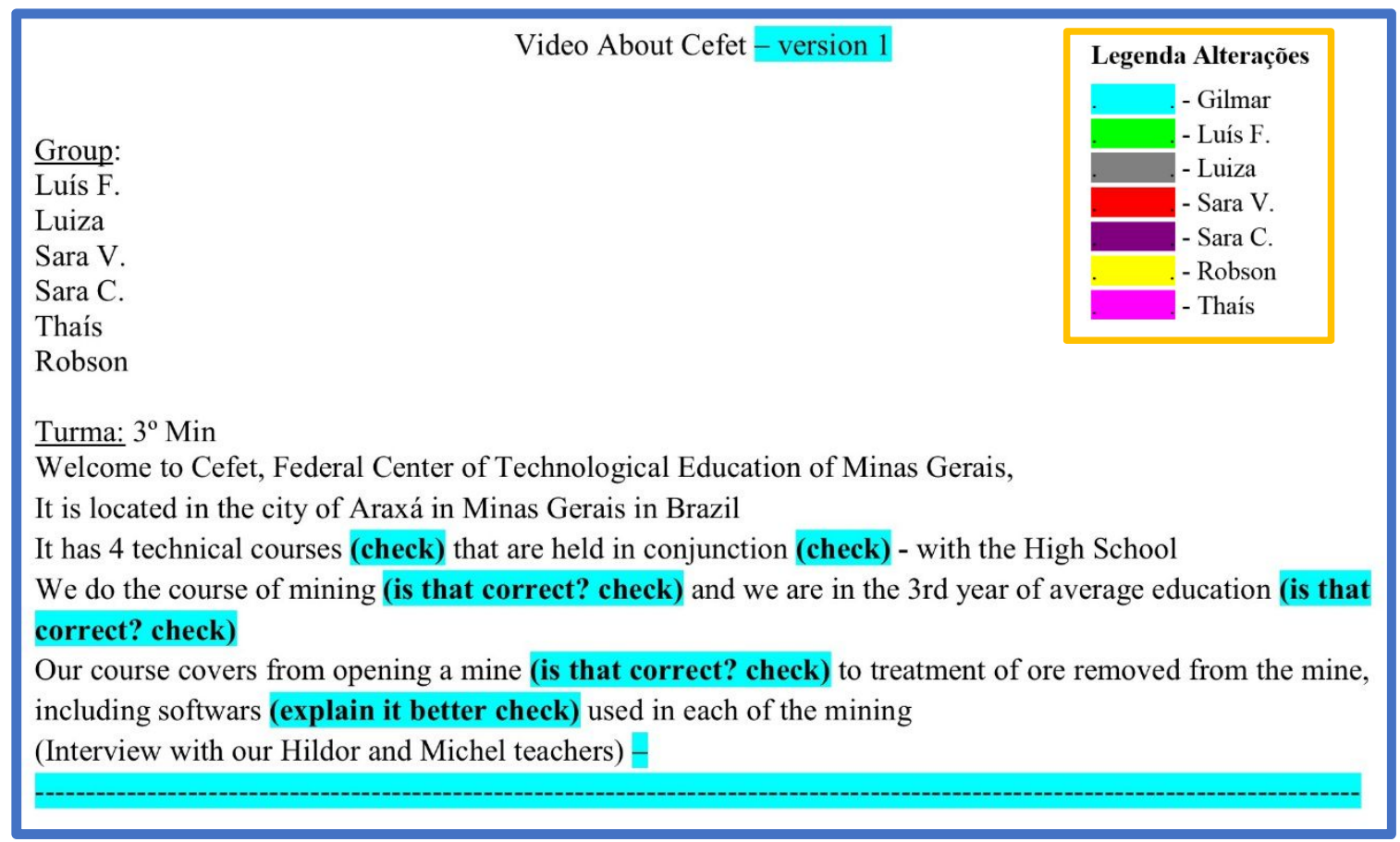

Fonte: print screen das marcações feitas no Google Docs

No laboratório, enquanto meus alunos liam as observações que eu havia feito (registros na cor azul), alguns disseram "Quem é esse Fernandes (nome do meu usuário no GD) que escreveu check no texto?", "Sou eu", respondi. "Ah, então todos nós podemos alterar no documento ao mesmo tempo", concluiu Luís F. Andei pelo laboratório e mostrei algumas funções do GD como o bate-papo, a possibilidade de saber quem estava fazendo as alterações, como formatar o texto e como visualizar versões anteriores do documento de texto.

Meus alunos usaram o tempo da aula pesquisando as questões que eu destaquei no script deles. "Nossa, mas esse Fernandes não para de escrever check, explain it better", reclamou Taís. Luíza, perguntou "Fernandes, tem alguma coisa certa no script? ", eu ri e disse "Sim, claro. Estou apenas apontando algumas questões que podemos melhorar".

Durante a aula, os alunos trabalharam para pesquisar as questões que eu havia destacado no texto deles, conforme pode ser observado no print screen da terceira versão a seguir. Luís F. (registros na cor verde) começou alterando o termo "average education" para "High School", termo em inglês adequado para se referir a ensino médio. Logo depois, colocou pontos finais em todas as frases, pois estavam sem. Continuou sua revisão se atentando para a formatação, excluindo espaços desnecessários, adicionando asteriscos ao final do documento para separar o texto principal de questões que poderiam 
ser adicionadas, apagando palavras desnecessárias e, ainda, adicionou o nome da turma no cabeçalho do documento.

Luíza (registros na cor cinza) começou corrigindo a ordem da palavra "teachers", que estava no final da frase, o que a deixava sem sentido. Depois, adicionou seu sobrenome na lista que estava no topo do documento. Thaís (registros na cor rosa) iniciou sua contribuição substituindo o numeral 4 para "four", forma por extenso do número quatro em inglês. Em seguida, colocou em letras maiúsculas o termo "Technicians Course". Luís F., novamente, se atentou à formatação e excluiu a palavra "check" que estava na frente do termo que Thaís acabara de alterar.

Eu estava sempre atento ao que os alunos escreviam no documento. Quando li "Technician Course", escrevi "check" e pedi para os alunos checarem esse termo em inglês, pois ele poderia não ser o mais adequado para se referir ao curso que meus alunos faziam.

\section{O script de uma história não registrada: conversas que não ficam salvas no GD}

Luís F.: Como assim não é "Technicians Course", professor?

Gilmar: Você achou esse termo em inglês?

Luís F.: Ainda não pesquisei, mas no Google Tradutor apareceu assim.

Gilmar: ok, mas, às vezes, o tradutor não identifica, ou sabe, que essas palavras devem se referir a uma categoria de profissionalização, por isso, ele pode ter traduzido apenas as palavras literalmente.

\section{Luíza se levantou e veio até meu computador}

Luíza: Olha aqui 'moço', eu achei um site que fala sobre "Technicians Course" e parece com o nosso.

Gilmar: Hum, não sei se é isso mesmo, por isso, estou escrevendo "check" na frente do termo de novo.

Thais, sem sair do lugar, perguntou inconformada:

Mas está errado de novo? A gente já achou um site que fala essas palavras em inglês.

Gilmar: Pesquisem novamente, pois vocês estão no Ensino Médio. Talvez esse "Technicians Course" não seja para alunos da idade de vocês.

Luís F.: Ok, vamos pesquisar de novo. Gente, não adianta discutir porque se ele está falando check é porque a gente tem que pesquisar e ele não vai dar a resposta.

Gilmar: Isso mesmo, Luís F.

Alguns alunos e eu rimos da situação.

Luíza: Acesse esse site aqui professor e você vai ver.

Gilmar: Já acessei e não é bem isso.

Luíza exclamou: Mas o que você quer então? Não estou entendendo.

Check, check, check e check, escrevi várias vezes para que pesquisassem novamente sobre esse termo.

Luíza perdeu a paciência algumas vezes e solicitava minha presença no computador dela.

Luíza: Teacher, vem aqui.

Gilmar: Estou indo, hold on.

Luíza: Não estou achando o que você quer.

Gilmar: Procure um pouco mais, você vai encontrar.

Luíza: Professor vem aqui no meu computador.

Gilmar: Luíza, você pode digitar aí no chat que eu visualizo daqui. Basta você escrever aí.

Luíza: Mas vem aqui, por favor. Eu prefiro.

Gilmar: Tudo bem, estou indo.

Algum tempo depois, Luíza começa a escrever ora no corpo do documento do GD, outra ora no chat. 
Gilmar: Muito bem Luíza, estou visualizando tudo que você escreve. Aguarde um pouco que irei te responder.

Luíza escreve no corpo do documento:

"Me ajuda!!! Não estou entendendo que palavra você quer"

Eu apaguei o que ela escreveu e disse: jogue no Google esse termo que vocês irão ver se ele é o termo mais adequado.

Luíza, brava, diz: "Que saco", vou ver. E para de apagar o que eu escrevo.

Eu ri de sua inquietação. Os alunos continuaram pesquisando até achar um termo mais adequado para se referir ao curso deles.

Luíza: Finalmente achei.

Luíza escreve no corpo do documento em letras garrafais: é "Mining Certificate Program".

Gilmar: "Voilà", eu disse que vocês achariam.

Thaís, com olhar penetrante, diz: Mas você podia, simplesmente, ter dito isso para gente.

Gilmar: Não, para que eu vou dar a resposta fácil assim? É importante vocês pesquisarem, e eu poderia estar errado.

(Reconstrução de memória - diálogos entre os alunos e o professor, outubro de 2016).

Luís F. prosseguiu seu trabalho apagando os "checks" das partes que eles já haviam verificado, e corrigindo nomes, que deveriam, mas que não estavam com letras maiúsculas. Em um determinado momento, ele trocou a palavra "four" para "4", desfazendo o que Thaís já havia corrigido. Logo depois, perguntou "Professor, como dizer terceiro ano do Ensino Médio? É 3rd year of High School?" "Não é não", respondi: "pesquise no Google”. "Ah, já achei, é 12th grade (sênior year). Obrigado”, ele disse em tom de brincadeira.

Continuei a leitura do texto que estavam produzindo. Quando li "We do the Mining Certification Program", escrevi depois de "do" para que eles checassem. Luíza, checou e mudou para "We are inserted on the Mining Certification Program". Logo depois, escreveu, novamente, em letras garrafais "olha aí querido professor a frase em rosa". Chequei e disse "ok, agora eu aceito".

Luís $F$. continuou seu trabalho destacando quais partes cada integrante do grupo narraria: "Luíza começará falando sobre o CEFET de forma geral. Thais irá fazer uma introdução sobre o Curso de Mineração. Logo em seguida, Luíza irá explicar o conceito de 'exploração e prospecção de minério'. Depois Thaís explicará sobre 'mineração de uma mina'. Para concluir, Luíza vai falar sobre 'processamento de minério' e Thaís sobre o software AutoCad".

A aula chegara ao fim e era hora de pararmos. Decidi deixar o restante da atividade para fazermos na próxima aula. Foi um dia produtivo, o script já havia mudado significativamente, conforme pode ser observado na terceira versão a seguir.

\section{Terceira versão do script}




\begin{tabular}{|c|c|}
\hline $\begin{array}{l}\text { Group: } \\
\text { Luís F. } \\
\text { Luiza D. } \\
\text { Sara V. } \\
\text { Sara C. - } \\
\text { Thaís } \\
\text { Robson } \\
\text { Turma: } \\
\end{array}$ & $\begin{array}{l}\text { Legenda Alterações } \\
\begin{array}{c}\text { - Gilmar } \\
\text { - Luís F. } \\
\text { - Luiza } \\
\text { - Sara V. } \\
\text { - Sara C. } \\
\text { - Robson } \\
\text { - Thaís }\end{array}\end{array}$ \\
\hline \multicolumn{2}{|c|}{ Luiza: Welcome to Cefet, Federal Center of Technological Education of Minas Gerais:- } \\
\hline \multicolumn{2}{|c|}{ It has 4 technical courses4 Certification Program (eheck) that are held in conjunetion (eheck) with the Higt } \\
\hline \multicolumn{2}{|c|}{$\begin{array}{l}\text { Thaís: We do-are inserted on the eourse of miningMining Certification Program (is that correet? cheek) } \\
\text { and we are in the-3rd year of average education (is that correct? cheek) }\end{array}$} \\
\hline \multicolumn{2}{|c|}{ High School: 12th grade (senior year). Our course covers from opening a mine (is that eorreet? eheek) te } \\
\hline \multicolumn{2}{|c|}{ treatment of ore removed from the mine, including softwars Our course aims to cover: } \\
\hline \multicolumn{2}{|c|}{ Luiza: Mineral prospecting and exploration, The first stage involves locating prospective deposits. To do thi } \\
\hline \multicolumn{2}{|c|}{ we use our knowledge of ore genesis and occurrence. Geologic environments that are associated with the } \\
\hline \multicolumn{2}{|c|}{ wanted type of mineral deposit are target of investigation. Methods such as geological surface mapping anc } \\
\hline \multicolumn{2}{|c|}{ potential deposits. After a deposit has been located, the next stage is to map the deposit in more detail to } \\
\hline \multicolumn{2}{|c|}{ evaluate grade and tonnage of the mineral occurrence. The deposit is then drilled to investigate and sample } \\
\hline \multicolumn{2}{|c|}{ the mineralization in depth. The density of the drilling is determined by the wanted level of geologic } \\
\hline \multicolumn{2}{|c|}{ Thaís: Mining of a mine. The processing is a process designed to improve the performance of an or } \\
\hline \multicolumn{2}{|c|}{ deposit.The aim is to eliminate inefficiency and waste by ensuring that the possible recoverable material is } \\
\hline \multicolumn{2}{|l|}{ extracted from the ore. } \\
\hline \multicolumn{2}{|l|}{ Luiza: Processing of ore } \\
\hline \multicolumn{2}{|l|}{ Thaís: Softwar(explain it better check) used in each of the mining } \\
\hline es like ArcGis and AutoCad & (Interview with our teachers, Hildor and Michelteachers). \\
\hline & \\
\hline
\end{tabular}

Fonte: print screen das alterações feitas no Google Docs

Comecei a aula seguinte com o habitual "Good afternoon", continuei "vamos para o laboratório novamente para concluir o script" e alguns reclamaram, mas eu disse "stop complaining". Sara C. perguntou "O que ele disse?" e seu colega respondeu "Pare de reclamar e vamos para o laboratório". Nessa aula, todos os integrantes do grupo estavam presentes, logo, Robson (registros na cor amarela), Sara V. (registros na cor vermelha) e Sara C. (registros na cor roxa) ${ }^{\vee}$ se juntaram na edição do script. Luís F., aparentemente, o 
diretor das cenas, redistribuiu as falas de cada participante do grupo de forma a inserir Sara V. e Sara C.

A revisão do documento começou com a contribuição de Luís F. apagando o nome de um dos professores do script, pois ele não seria mais entrevistado para essa atividade. Eu, como de costume, li o documento e comecei a questioná-los sobre o que haviam escrito "ArcGis e AutoCad? What is it??? Explain it". Luiza, tentando me entender questiona "você só está curioso ou realmente precisa escrever aqui?" "Sim, you are supposed to write here", respondi. Luíza, não se contentou e disse "qual a necessidade de explicar o que são depósitos minerais?". Pacientemente, eu respondi "é importante porque não é todo mundo que sabe a que você está se referindo".

Sara V. começou sua contribuição no script apagando os espaços em excesso entre um parágrafo e outro, já Robson iniciou corrigindo o trecho "the processing is a process", pois "o processamento é um processo" não fazia sentido. Assim, ele alterou a frase para "The ore processing is a process designed to improve the performance of an ore deposit" e, ao fazê-lo, explicou que o processamento de minério é realizado para melhorar a performance de um depósito de minério.

Luíza, novamente, agora com o auxílio da Sara C., chamava frequentemente minha atenção dizendo, em letras garrafais no corpo do documento, "HELP!!! Olha o que eu escrevi e vê se está certo. E agora? TA BOOOOOOOOOM? Is it correct now????????". Eu lia e pedia que ela pesquisasse um pouco mais. Em um determinado momento, ela pesquisou sobre o nome do curso dela em inglês e pediu que eu olhasse novamente, mas dessa vez disse "seja legal". Antes que eu terminasse de ler, ela acrescentou "se não entendeu posso te mandar um link por email explicando".

No parágrafo seguinte, Robson pesquisava algumas questões que eu havia apontado, como traduções que precisavam ser revisadas, e alterava questões gramaticais, de ordem de palavras, preposições e outras. Em sua primeira correção, trocou "consist of seek operations that modify", que não fazia sentido em português e inglês, para "consist of operations that seek to modify", explicando, portanto, que o beneficiamento de minério consiste em operações que buscam, dentre outras funções, modificar o tamanho da partícula de minério.

Em um de seus primeiros registros no script, Sara C. respondeu à pergunta "TA BO००0०००००M? " de Luíza, direcionada a mim, dizendo "Tá sim", mas logo apagou o que havia escrito. Sua colega Sara V., impaciente escreveu no corpo do script perguntado 
"você quer um artigo em English?????????". Eu, para não perder a piada, respondi "nope ()".

Robson, caracteristicamente mais reservado e calado, fez alterações de ordem gramatical em trechos diferentes do script, independentemente de quem fosse falar aquele trecho no vídeo. Quase no final da aula, os alunos leram o script e acreditaram que ele estava pronto. Assim, disseram "pronto, chega. Acabamos". Eu, ciente de que o script seria narrado durante um vídeo, Ihes questionei "Mas como vocês vão terminar o vídeo? Não vão falar nada? Sequer um bye?"

Luíza afirmou "Não, não vamos falar nada". Luís F., então, adicionou uma frase curta de fechamento no final do script "This is our video, we hope you liked our school" e Thaís acrescentou "Bye Bye. XOXO". Olhei, mais uma vez o documento, com o texto produzido, e concluí de que ele, agora, se parecia com um script, conforme pode ser observado em sua versão final a seguir.

\section{Versão final do script}

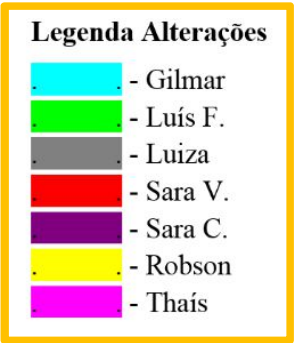


Group:

Luís F.

Luiza

Sara V.

Sara C.

Thaís

Robson

EtrizaSara V.: Welcome to Cefet-Federal Center of Technological Education of Minas Gerais).It has 4

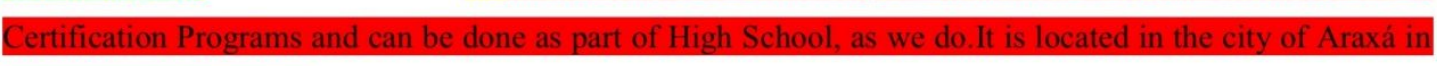

Minas Gerais in Brazil.

Sara C.: We are inserted on the Mining Certification Program and we are in the High School: 12th grade

(senior year). Our course aims to cover, the understanding of natural phenomenons, that cause, and are caused

by geologic alterations on earth,
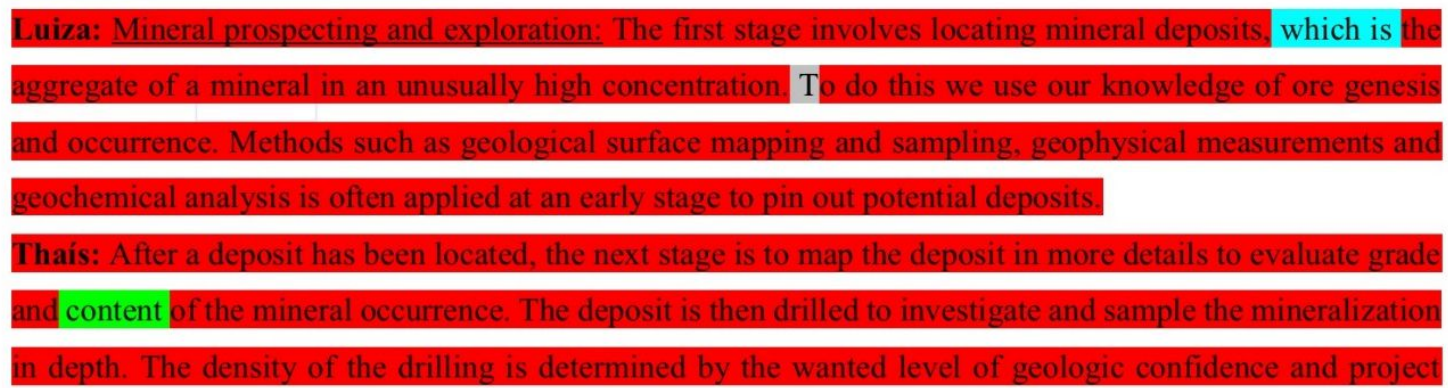

economics.

Luiza: Mining of a mine: There are two types: surface mining and underground mining. Surface mining is the process that is done by removing surface vegetation, dirt, and, if necessary, layers of bedrock in order to reach buried ore deposits, but always at ground level. Underground mining consists of digging tunnels or shafts into the earth to reach buried ore deposits.

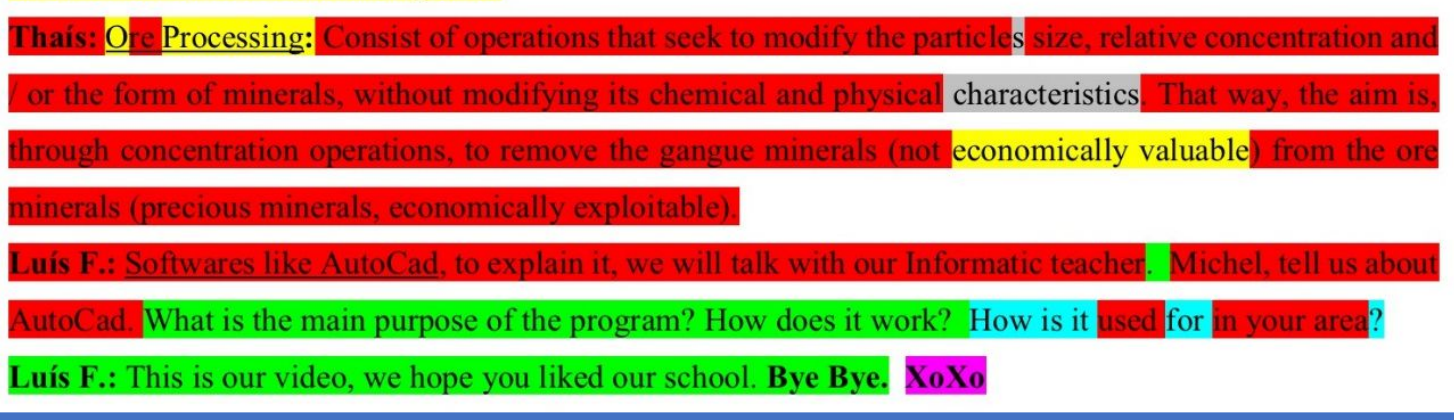

Fonte: print screen das alterações feitas no Google Docs

\section{COMPONDO SENTIDO DAS EXPERIÊNCIAS VIVIDAS}

As experiências narradas anteriormente me possibilitaram compor sentidos sobre o processo de escrita colaborativa por meio do Google Docs. Diferentemente dos resultados encontrados por Weissheimer, Bergsleithner e Leandro (2012), os participantes desta pesquisa se preocuparam, a priori, com questões de ordem gramatical e linguística ao 
elaborarem o script. Ademais, eles contaram com minha interferência na realização da atividade, o que contribuiu para que eles se atentassem às especificidades do gênero script. As questões discursivas e estruturais do gênero só foram percebidas pelos alunos após minha interferência. Hoje, ao recordar as instruções que dei aos estudantes, percebo que me preocupei em sanar as dúvidas relacionadas a questões técnicas e de execução da atividade e, ingenuamente, não discuti com a turma sobre o gênero em questão porque pressupus que o script era um gênero bem conhecido por eles.

Essa experiência me possibilitou observar um aspecto com relação ao uso do Google Tradutor. Nas orientações para a atividade e em minhas aulas, frequentemente, eu falava para os alunos que o tradutor é uma ótima ferramenta para tradução, mas que não podemos usá-lo como única fonte de pesquisa, tal como apontado por Fernandes e Freitas (2015). No entanto, por eu acreditar que essa é uma informação de conhecimento geral, apenas falava superficialmente sobre ela. Ao fazê-lo, eu não contribuía para que os alunos entendessem empiricamente ao que me referia. Quando os levei para o laboratório e eles puderam experienciar um processo de reescrita a partir de outros recursos da internet, além do tradutor, eu percebi que começaram a entender o que eu queria dizer sobre o uso do tradutor. Era comum, por exemplo, eles dizerem "Agora eu entendi o que você quis dizer" ou "O tradutor está errado? Vou pesquisar em outro site, então".

Luíza, por exemplo, teve muita dificuldade para entender que a tradução do nome do curso dela, em inglês, poderia não ser exatamente Technician Course. Embora esse termo exista em inglês e esteja correto, a nomenclatura Certificate Program é mais comumente utilizada na língua inglesa para se referir a um curso de nível médio e técnico. Por isso, frequentemente, ela ficava impaciente quando eu escrevia "Is that correct? Check" e pedia que ela pesquisasse mais um pouco, em outros sites. Quando, finalmente, ela encontrou uma explicação na internet a respeito da tradução de Curso Técnico, foi possível ver o alívio em seu olhar.

Semelhantemente à Luíza, Thaís ficava inquieta com meus questionamentos nos trechos que eles escreveram, provavelmente tendo o Google Tradutor como fonte principal de pesquisa. Em um determinado momento, ela disse "Tem alguma coisa certa no script? ". Luís F. questionou algumas vezes os apontamentos que eu havia feito, mas parecia entender um pouco mais minhas indagações, desse modo, rapidamente voltava ao computador para pesquisar em outros sites. Sara V. questionou apenas uma vez dizendo "Você quer um artigo em English?". Segundo Machado (2009a), o GD é uma ferramenta digital que favorece a interação entre os usuários, por isso, eles têm 
possibilidade de serem autores de um texto produzido em conjunto, de discordar, acrescentar e retirar conteúdos, tais como fizeram Luís $\mathrm{F}$., Thaís e Luíza, por exemplo.

Sara C. e Robson não questionaram meus apontamentos. Robson, contudo, na segunda aula, pesquisou várias questões que eu havia apontado no documento. Hoje, relembrando sua participação autônoma, sem meu auxílio, percebo que eu poderia ter dado um pouco mais de atenção a ele e perguntado se eu poderia ajudá-lo. Em alguns momentos, embora eu estivesse no laboratório, eu me vi sobrecarregado com a atividade, pois eu estava lendo e fazendo comentários, ao mesmo tempo, em três scripts diferentes. Talvez pelo medo de não deixar que os alunos achassem que eu não estava lendo suas correções, eu estava freneticamente focado nos scripts dos três grupos ao mesmo tempo.

Conforme Dillenbourg (1999), um trabalho colaborativo envolve um "contrato" no qual está implícito que os membros de um determinado grupo trabalharão em equipe para solucionar um problema. Partindo de algumas de minhas experiências como professor de língua inglesa, observei algumas vezes a prática recorrente de um aluno mais proficiente ficar encarregado de ler e traduzir os textos em inglês, enquanto os demais integrantes do grupo não tinham grandes participações. Por isso, eu acreditava que um ou outro aluno faria toda a tarefa do script. Então, por almejar que todos participassem da atividade de escrita, decidi levá-los ao laboratório para construirmos juntos o script. Ao fazê-lo, observei que todos os integrantes do grupo se envolveram na atividade, pois, embora houvesse alguns alunos que, aparentemente, eram mais proficientes que outros, os demais participantes contribuíram, mesmo que de formas diferentes e diversificadas, tais como corrigindo questões de acentuação e formatação do texto.

Destarte, tendo em mente as definições de Dillenbourg (1999) sobre a aprendizagem colaborativa, acredito que, nesta pesquisa, o processo de colaboração entre meus alunos e eu pôde favorecer a aprendizagem, o que remete à concepção de colaboração como processo psicológico. Minha crença a esse respeito se deve ao fato de que, ao solicitar que os alunos pesquisassem na internet as questões que precisavam ser revistas, ao invés de dar as respostas prontas ou fazer as alterações no texto, eu os instiguei a pesquisar, interagir e auxiliar uns aos outros, o que, talvez, favoreceu sua aprendizagem.

Considerando as definições de colaboração e cooperação propostas por Roschelle e Teasley (1995), foi possível perceber que a colaboração foi predominante nessa atividade, uma vez que o grupo trabalhou em conjunto para solucionar e corrigir os vários apontamentos que eu fiz no texto deles. Embora seja possível determinar, 
quantitativamente, as contribuições de cada aluno, não houve uma divisão de atividades em que cada participante do grupo seria responsável apenas por uma tarefa específica, estanque. Luís F., Luíza, Thaís e Robson, por exemplo, fizeram alterações e contribuições de todas as ordens e alternaram entre alterações de ordem gramatical, estrutural, correções de espaçamento, ordem de palavras, correção de letras maiúsculas e minúsculas e troca de termos inadequados.

Com essa experiência, depreendi que, em um trabalho cujo o foco seja a prática da escrita em língua inglesa, é necessário que o professor discuta bem com os alunos quais contribuições serão avaliadas nesse trabalho. Embora todas as contribuições citadas anteriormente sejam importantes para uma escrita colaborativa, é importante que o professor estabeleça qual será o foco de sua atenção no processo avaliativo. Eu, particularmente, pressupus que todos os alunos dariam, dentre outras, contribuições de ordem linguística-gramatical. No entanto, ao ver o histórico das alterações, não foi o que identifiquei. Por isso, por eu não ter discutido a esse respeito, na avaliação, eu considerei as contribuições de todas as ordens.

Descobri, pela prática, que os chats não ficam registrados no GD para que possamos consultá-los posteriormente e que, caso alguém apague o texto, não é possível recuperar versões anteriores do documento. Nessa experiência de (re) escrita, eu desconhecia essa informação porque foi a primeira vez que utilizei o GD como ferramenta de escrita colaborativa. Portanto, nesta pesquisa, especificamente, perguntei aos participantes do grupo o que eles haviam conversado pelo chat, os quais me externaram que não havia nada de produtivo nele, pois, como estavam, no mesmo ambiente, no laboratório de informática, não viram a necessidade de interagir por meio dele. Sendo assim, percebi que é importante que o professor considere esses aspectos, pois, pode ser que os alunos discutam sobre o texto a ser produzido pelo chat, mas que apenas um ou outro faça as alterações no documento.

De acordo com Luckesi (2000), a avaliação da aprendizagem vai para além de um exame final, atrelado exclusivamente à nota, e deve ser processual e construtiva. Assim, como eu objetivava avaliar o trabalho em equipe, a colaboração na escrita do script, e o engajamento individual na realização da atividade, durante o processo avaliativo, eu precisei considerar outras formas de avaliação: uma autoavaliação, uma avaliação de grupo, as alterações feitas no documento e que ficaram registradas e, também, minhas lembranças das aulas que usamos para realizar essa atividade. 
Por se tratar de um documento de escrita que pode ser compartilhado por meio de links, o GD oferece a possibilidade de edição para qualquer pessoa que tenha acesso ao link. Em minha experiência com meus alunos, eu queria que ficasse registrado quem fez as alterações para que eu pudesse acompanhar se todos estavam colaborando na construção do script. Por isso, eu compartilhei um link em que eles precisariam se conectar com uma conta de e-mail. Contudo, alguns deles não tinham conta do Gmail ou Yahoo, que, nesse caso, são os únicos que o GD permite que os usuários se conectem. Então, alguns alunos usaram uma conta geral da turma, criada por mim para utilizarmos todas as vezes que uma plataforma exigisse acesso por meio de um e-mail.

Entretanto, por se tratar de um e-mail coletivo, houve casos em que dois alunos, ou mais, estavam conectados com o e-mail da turma, então, pelos registros salvos no GD, às vezes, não foi possível identificar o aluno que fez determinadas alterações, o que, em um processo avaliativo que consideraria apenas as alterações registradas no GD, poderia prejudicar um aluno ou outro. Assim, essa experiência me ensinou que, em alguns casos, pode ser relevante dedicar um tempo da aula para que, aqueles alunos que não tem email do Gmail ou Yahoo, criem uma conta em um desses provedores.

Com essa experiência compreendi o quão importante é que o professor discuta com os alunos sobre os aspectos que serão avaliados no GD. Como dito anteriormente, há alunos que focaram suas correções em questões de ordem organizacional e estrutural do texto, mas o objetivo da atividade era que eles praticassem questões de ordem linguística da língua inglesa. Acredito que, por eu não ter discutido com os alunos a esse respeito, alguns não se preocuparam em registrar no corpo do GD as alterações feitas por eles e, principalmente, não focaram nas questões linguísticas. Eu observei esse aspecto posteriormente à realização da atividade, a partir do feedback de um dos alunos de outro grupo, que externou que não se sentia confiante para fazer as alterações linguísticas, então, ele deixou que os colegas, que ele acreditava serem mais proficientes, fizessem essas alterações.

Com a história secreta, narrada anteriormente, constatei que o trabalho em grupo é, por vezes, dividido entre os membros do grupo e que, nem sempre, o professor consegue perceber que as tarefas foram divididas. Destarte, é importante que o professor pergunte ao grupo como eles se organizaram para realizar a tarefa. Ademais, devido a hipertextualidade predominante em ambientes online, os usuários têm desenvolvido, cada vez mais, a habilidade e o hábito de realizar mais de uma atividade por vez. Por outro lado, há usuários que não possuem o letramento digital para gerenciar o tempo gasto em 
cada ambiente e a habilidade de manter o foco nas atividades principais. Por isso, aprendi que, em alguns momentos, "vigiar" o que alguns alunos estão fazendo pode contribuir para que eles se engajem e foquem mais na atividade. No entanto, a "vigilância" não é necessária para todos os alunos, haja vista há aqueles que se empenham na atividade sem, necessariamente, precisar da cobrança do professor.

Considerando que "colaboração é uma atividade síncrona e coordenada que é o resultado de uma tentativa contínua de construir e manter uma concepção compartilhada de um problema" (ROSCHELLE E TEASLEY, 1995, p. 70), nesse processo de escrita, eu senti a necessidade de questionar os alunos sobre várias questões que constavam no texto para que, juntos, pudéssemos alcançar um objetivo comum: um script em língua inglesa. Ao pensar sobre meu papel nessa atividade, percebo que fui, algumas vezes, coautor do script elaborado, pois, eu poderia ter corrigido as versões e entregue para os alunos. Contudo, fui com eles ao laboratório para que eles, com meu auxílio, pesquisassem várias questões que poderiam ser aprimoradas. Quando questionei Thaís, por exemplo, sobre o porquê de o grupo ter se empenhado tanto na atividade, ela externou que era porque eu era exigente. A meu ver, sua percepção se remete ao fato de eu estar presente na atividade com eles, lendo, algumas vezes corrigindo, questionandoos e, assim, colaborando com o grupo.

\section{CONCLUSÃO}

Ante às histórias narradas e os sentidos compostos neste artigo, percebi que o GD pode ser uma ferramenta digital pertinente para o desenvolvimento da habilidade de escrita. Contudo, por meio da experiência vivida com meus alunos, identifiquei que a ferramenta pode também contribuir significativamente para o desenvolvimento de aspectos relacionais, tais como (in) dependência entre os alunos, alternância de papeis e negociação-distribuição de tarefas. Como afirma Dewey $(1938,1979)$, há vários aspectos relacionados em um processo educativo e não apenas o contexto, material e, no nosso caso, a ferramenta. Além disso, constatei que o planejamento de uma atividade por meio GD pode trazer grandes contribuições para a construção de conhecimentos em língua inglesa, a depender da forma como a atividade é planejada e conduzida.

Conforme apontado por Weissheimer et al (2012), a atividade de escrita por meio da ferramenta GD pode contribuir para tirar o foco do produto final a ser produzido, o texto, e chamar a atenção para o processo de escrita. Nesse sentido, minha experiência me possibilitou perceber que, ao tirar o foco do produto e colocá-lo no processo, foi 
possível estimular o desenvolvimento de uma atividade de forma colaborativa e, assim, permitir que os alunos interagissem, entre si e comigo, e, possivelmente, construir conhecimentos em conjunto.

Em sua pesquisa, Weissheimer et al (2012) afirmam que, provavelmente, a não interferência dos professores no processo de escrita dos alunos contribuiu para que eles focassem em questões do gênero em detrimento de aspectos formais da língua inglesa. Diferentemente, acredito que, em minha experiência, ao assumir o papel de professor colaborador no processo de escrita, e não de detentor ou transmissor do conhecimento, eu posso ter contribuído para que os alunos se atentassem para questões de todas as ordens (gramaticais, discursivas, do gênero e outras).

Em suma, a despeito do processo de escrita vivido pelos alunos e eu, analisado nesta pesquisa, é possível afirmar que houve colaboração no desenvolvimento da atividade, tendo em vista que todos os alunos se envolveram para construir um script em conjunto, colaborativamente. Todavia, as diferentes alterações e contribuições de cada aluno no texto produzido me levam a questionar se houve escrita colaborativa. Considerando que eu participei do processo de (re) escrita somente após a primeira versão criada pelos alunos e, pelas experiências narradas neste artigo, é possível afirmar apenas que os alunos contribuíram de formas diferentes. Assim, esta é uma limitação deste estudo que, em outra oportunidade, poderei me atentar.

\section{REFERÊNCIAS}

AFONSO, C. A. Internet no Brasil: alguns desafios a enfrentar. Informática Pública. Belo Horizonte, v. 4, n. 2, p. 169-184, 2002.

BEDRAN, P.F. A escrita colaborativa em um contexto de formação de professores de língua. Raído, v.9, n. 18, p. 59-84, 2015.

CAINE, V.; CALNDININ, D. J. Narrative Inquiry. In: Trainor, A; Graue, E. (Eds.).

Reviewing qualitative research in the social sciences: a guide for researchers and reviewers. New York, NY. pp. 166 - 179, 2013.

CLANDININ, D. J. Handbook of Narrative Inquiry: mapping a methodology. SAGE Publications, p. 693, 2007.

.Engaging in Narrative Inquiry. United States: Left Coast Press, 2013.

CLANDININ, D. J.; CONNELLY, F. M. Asking questions about telling stories. In: Writing Educational Biography: explorations in qualitative research. Critical Education

Practice(vol.13), Garland Reference Library of Social Science, Volume 1098, New York and London. Pp:245- 253, 1998. 
Narrative inquiry: experience and story in qualitative research. San Francisco: Jossey-Bass Publishers, 2, 2000.

.Pesquisa narrativa: experiências e história na pesquisa qualitativa; Tradução: Grupo de Pesquisa Narrativa e Educação de Professores ILEEL/UFU. - Uberlândia, EDUFU, 2011, p. 250.

CLANDININ, D.J.; PUSHOR, D.; ORR, A. M. Navigating sites for narrative inquiry. In. Journal of Teacher Education, v.58, n.1, p. 21-35, 2007.

CONNELLY, M.; CLANDININ, D.J. Stories of experience and narrative inquiry. Educational Researcher, 19 (5), pp.2-14, 1990. 1994.

.Telling teaching stories. Teacher Education Quarterly, v. 21. n.1, pp. 145-158,

DEWEY, J. Criteria of experience. In. Experience and Education. New York: Collier Books, 1938.

DILLENBOURG, P. What do you mean by collaborative learning? In (Ed)

Collaborative-learning: Cognitive and Computational Approaches. Oxford: Elsevier, p.119, 1999.

ELY, M.; VINZ R.; DOWNING, M.; ANZUL, M. 2001. On writing qualitative research: living by words. London and Philadelphia: RoutledgeFalmer, 411p.

FERNANDES, G. M. F. Era uma vez um professor de inglês recém-formado, um mestrado e um curso de extensão sobre tecnologias digitais. 2014. $146 \mathrm{f}$. Dissertação (Mestrado em Estudos Linguísticos) - Instituto de Letras e Linguística, Universidade Federal de Uberlândia, Uberlândia, 2014.

FERNANDES, G. M. F.; FREITAS, D. M. O Google Tradutor E Suas Funções: Ressignificando A Ferramenta Para Tradução. Artefactum - Revista de Estudos em Linguagem e Tecnologia, n. 2, 2015.

FIGUEIREDO, F.J.Q.; SILVA, S.V. Interações telecolaborativas na aprendizagem de línguas estrangeiras: foco no uso dos recursos do aplicativo computacional Open meetings. Ilha do desterro, n.66, p. 133-172, 2014.

KING, T. You're not the Indian I had in mind. In: The truth about stories: a native narrative. House of Anansi Press Inc. Pp: 1- 60, 2003.

LAMY, M.N.; HAMPEL, R. Teaching online. In: Online communication in language learning and teaching. New York: Palgrave Macmillan, 2007, p. 61-75.

LUCKESI, C. C. O que é mesmo o ato de avaliar a aprendizagem? In Pateo Revista Pedagógica, Artemed. Porto Alegre/RS, v. 4, n.12, p. 6-11, 2000.

MACHADO, A.C.T. A ferramenta Google Docs: construção do conhecimento através da interação e colaboração. Revista Paidéi@, UNIMES VIRTUAL, Volume 2, número 1, jun. 2009a. 
Google Docs \& Spreadsheets: Autoria colaborativa na web 2.0. e-tec

Revista Científica do Departamento de Tecnologia do UNI-BH, v. 2, p. 1-12, 2009b.

MELLO, D. M. Histórias de subversão do currículo, conflitos e resistências:

buscando espaço para a formação do professor na aula de Língua inglesa do curso de Letras. 2004. 225 f. Tese (Doutorado em Linguística Aplicada e Estudos da Linguagem) LAEL, Pontifícia Universidade Católica de São Paulo, São Paulo, 2005.

.Curriculum, Teacher Education and Narrative Inquiry. In: Paris International Conference on Education, Economy \& Society, 2008, Paris. Conference Proceedings. Paris: Analytics, 2008. v. 1. p. 2-12.

.The Language of Arts in a Narrative Inquire Landscape. In: Jean Clandinin. (Org.). Handbook of Narrative Inquiry: mapping a methodology. 1ed.Florida: Sage Publications Inc, 2007, v. 1, p. 203-223.

.English Teacher Education, Curriculum and Narrative Inquiry. In: Betânia Passos Medrado; Carla Lynn Reicgman. (Org.). Projetos e Práticas Na Formação de Professores de Língua Inglesa. $1^{\mathrm{a} e d . J o a ̃ o ~ P e s s o a: ~, ~ 2012, ~ v . ~ 1, ~ p . ~ 02-253 . ~}$

Subversão do Currículo e Formação de Professores: ensinando e aprendendo língua inglesa no curso de Letras. 1 $^{\text {a }}$. ed. Uberlândia: Dilma Mello, 2012. v. 1000. 224p.

.Etnografia, Pesquisa Narrativa e Fenomenologia: entendendo espaços de fronteira entre três caminhos de pesquisa. In: Rosinei de Cordeiro; Luciana Kind. (Org.). Narrativas, Gênero e Política. 1ed.São Paulo: Editora CRV, 2016, v. p. 7-38.

ONRUBIA, J.; COLOMINA, R.; ENGEL, A. Os ambientes virtuais de aprendizagem baseados no trabalho em grupo e na aprendizagem colaborativa. In: (org) Psicologia da educação virtual. Aprender e ensinar com as tecnologias da informação e da comunicação. Porto Alegre: Artmed, 2010, p. 208-225.

ROSCHELLE, J.; TEASLEY, S. The construction of shared knowledge in collaborative problem solving. In: C. F. O'Malley (Ed.), Computer supported collaborative learning. New York: Springer-Verlag, 1995, p. 69-97.

WEISSHEIMER, J.; BERGSLEITHNER, J. M.; LEANDRO, D. C. Escrita colaborativa com Googledocs na aprendizagem de inglês como língua adicional. In: Beck, M. S.; Silveira, R.; Funck, S. B.; Xavier, R. P. (Org.). Anais do III Congresso Internacional da ABRAPUI. Universidade Federal de Santa Catarina. Florianópolis, 2012.

Artigo recebido em 15/08/2017

Artigo aceito em 28/11/2017

\footnotetext{
${ }^{\mathrm{i}} \mathrm{O}$ Google Docs é um documento gratuito de criação e edição de textos online que permite, dentre outras funções, a escrita simultânea entre vários usuários, o compartilhamento por meio de links de um mesmo documento de texto e o registro detalhado das alterações feitas no documento.
} 


\footnotetext{
ii Esta pesquisa foi motivada pela disciplina Tecnologias, Ensino e Aprendizagem de Línguas ministrada pela Profa. Dra. Fernanda Costa Ribas no Programa de Pós-Graduação em Estudos Linguísticos da Universidade Federal de Uberlândia, no ano de 2016.

iii O vídeo produzido pelo grupo pode ser visto em: $<$ https://www.youtube.com/watch?v=edTA23JLzsU $>$. Acesso em: novembro 2016.

${ }^{i v}$ Ambas as traduções são de minha autoria.

${ }^{\mathrm{v}}$ Neste artigo, trago apenas os print screens das versões finais de cada dia, por essa razão, as alterações feitas por Sara

C. não aparecem nas imagens.
} 